\title{
KELAYAKAN BUKU AJAR MATA KULIAH PEMBELAJARAN IPA SD BAGI MAHASISWA PGSD
}

\author{
Nelly Wedyawati ${ }^{1}$, Yasinta Lisa ${ }^{2}$ \\ ${ }^{1}$ Program Studi PGSD STKIP Persada Khatulistiwa Sintang, Jalan Pertamina Km. 4 \\ ${ }^{2}$ Program Studi Ilmu Komputer STKIP Persada Khatulistiwa Sintang, Jalan Pertamina Km. 4 \\ 1e-mail: tanpittjun@gmail.com
}

\begin{abstract}
Abstrak
Penelitian bertujuan mengetahui kelayakan dan efektivitas buku ajar pembelajaran IPA SD untuk mahasiswa PGSD. Indikator kelayakan pakar Pembelajaran; isi, penyajian, dan kebahasaan. Indikator kelayakan pakar media; ukuran buku ajar, desain cover, dan desain isi. Indikator kelayakan dosen adalah kejelasan, kesesuaian dengan kurikulum, keutuhan penerimaan, pengaruh produk, ketepatan waktu dan kepraktisan. Tahapan penelitian $R \& D$; studi pendahuluan, perancangan produk, validasi pakar, implementasi produk dan sosialisasi. Alat pengumpul data; angket, soal tes, dan dokumentasi. Data kualitatif dianalisis dengan hitungan persentase. Data kuantitatif diujiprasyaratkan dan uji hipotesis. Hasil menunjukkan produk sangat baik $(96,1)$, penilaian dari pengguna buku sangat baik $(90,1)$. Hasil implementasi menunjukkan sebaran data normal dan tidak homogen. Sehingga uji hipotesis menggunakan uji non parametrik diperoleh nilai $p$-level $(0.000)<$ alpha artinya ada pengaruh penggunaan produk terhadap hasil belajar. Rata-rata hasil belajar sangat baik $(95,31)$. Kesimpulannya bahwa buku ajar mata kuliah pembelajaran IPA di SD sudah layak dan efektif untuk diimplementasikan.
\end{abstract}

Kata Kunci: buku ajar, pembelajaran IPA, mahasiswa, PGSD.

\begin{abstract}
The aim of the study was to assess the feasibility of textbooks for science learning course in Primary schools for college students in the PGSD. Indicators of feasibility by science learning are content, presentation and language. Feasibility indicators by media experts are the size of textbooks, cover design and content design. Feasibility indicators for lecturer were clarity, suitability with the curriculum, integrity of acceptance, product influence, timeliness and practicality. The research stages of $R \& D$ were preliminary studies, product design, experts validation, product implementation and product socialization. Instrument for data collection were questionnaires, test and documentation. Qualitative data was analyzed by percentage and quantitative data would be tested and hypothesis tested. The results of the study showed that the experts assessment of the product was in very good (96.1), the assessment of the lecturer and college students as users of the textbook was very good (90.1). the results of product implementation show normal and not homogeneous data distribution. So that the hypothesis test uses the non-parametric and obtained the p-level (0.000) <alpha, this means that there is an influence of product use on learning outcomes. The average score of the learning outcomes was in very good (95.31). The conclusion is that the textbooks of science learning courses in primary schools are feasible to be implemented and used.
\end{abstract}

Keywords: textbook, Science Learning, college students, PGSD. 


\section{PENDAHULUAN}

Buku ajar adalah sebuah karya tulis yang berbentuk buku dalam bidang tertentu, yang merupakan buku standar yang digunakan guru dan mahasiswa dalam proses belajar mengajar untuk maksud-maksud dan tujuan instruksional, yang dilengkapi dengan sarana-sarana pengajaran yang serasi dan mudah dipahami (Suroso, 2004). Adanya buku ajar perkuliahan akan membantu mahasiswa dalam hal penyampaian materi dan pemahaman konsep. Buku ajar diharapkan memberikan kemudahan, yang mememuat model pembelajaran hingga evaluasinya (Kurniasih, 2016). Buku ajar merupakan salah satu sarana keberhasilan proses belajar mengajar.

Buku ajar berisi informasi, pembahasan serta evaluasi. Buku ajar yang tersusun secara sistematis akan mempermudah peserta didik dalam materi sehingga mendukung ketercapaian tujuan pembelajaran. Buku ajar harus disusun secara sistematis, menarik, aspek keterbacaan tinggi, mudah dicerna, dan mematuhi aturan penulisan yang berlaku. Dengan adanya buku ajar kegiatan belajar mengajar di sekolah menjadi lebih lancar dan efektif.

Sebagai calon guru, mahasiswa Pendidikan Guru Sekolah Dasar (PGSD) wajib menguasai semua mata kuliah, termasuk mata kuliah Ilmu Pengetahuan Alam (IPA). Hal tersebut bertujuan untuk menghasilkan generasi dewasa yang menguasai sains sehingga dapat menghadapi tantangan hidup dalam dunia yang makin kompetitif, mampu turut serta memilih dan mengolah informasi untuk digunakan dalam mengambil keputusan.

IPA didefinisikan sebagai kumpulan pengetahuan yang tersusun secara terbimbing yang berhubungan dengan cara mencari tahu tentang alam secara sistematis, sehingga bukan hanya penguasaan kumpulan pengetahuan yang berupa fakta, konsep, atau prinsip saja tetapi juga merupakan suatu proses penemuan (Samatowa, 2011). IPA juga merupakan ilmu yang bersifat empirik dan membahas tentang fakta serta gejala alam. Fakta dan gejala alam tersebut menjadikan pembelajaran IPA tidak hanya verbal tetapi juga faktual. Hakikat IPA sebagai proses diperlukan untuk menciptakan pembelajaran IPA yang empirik dan faktual. 
Hakikat IPA sebagai proses diwujudkan dengan melaksanakan pembelajaran yang melatih keterampilan proses bagaimana cara produk sains ditemukan. Menurut pandangan konstruktivisme dalam proses pembelajaran IPA disediakan serangkaian pengalaman berupa kegiatan nyata yang rasional atau dapat dimengerti siswa dan memungkinkan terjadi interaksi sosial (Wedyawati, Lisa dan Selimawati, 2017).

Tujuan pembelajaran IPA di SD secara terperinci adalah: (1) Memperoleh keyakinan terhadap kebesaran Tuhan Yang Maha Esa berdasarkan keberadaan, keindahan, dan keteraturan alam ciptaann-Nya; (2) Mengembangkan pengetahuan dan pemahaman konsep-konsep IPA yang bermanfaat dan dapat diterapkan dalam kehidupan sehari-hari; (3) Mengembangkan rasa ingin tahu, sikap positif, dan kesadaran tentang adanya hubungan yang saling memengaruhi antara IPA, lingkungan, teknologi, dan masyarakat; (4) Mengembangkan keterampilan proses untuk menyelidiki alam sekitar, memecahkan masalah, dan membuat keputusan; (5) Meningkatkan kesadaran untuk berperan serta dalam memelihara, menjaga, dan melestarikan lingkungan alam dan segala keteraturannya sebagai salah satu ciptaan Tuhan; dan (7) Memperoleh bekal pengetahuan, konsep, dan keterampilan IPA sebagai dasar untuk melanjutkan pendidikan ke SMP atau MTs.

Ruang lingkup bahan kajian IPA di SD secara umum meliputi dua aspek, yaitu kerja ilmiah dan pemahaman konsep. Lingkup kerja ilmiah meliputi kegiatan penyelidikan, berkomunikasi ilmiah, pengembangan kreativitas, pemecahan masalah, sikap, dan nilai ilmiah (Rizema, 2013). Sains terbentuk dan berkembang melalui suatu proses ilmiah. Dalam pembelajaran sains, proses ilmiah tersebut harus dikembangkan terhadap mahasiswa sebagai pengalaman yang bermakna.

Mata kuliah Pembelajaran IPA di SD adalah mata kuliah wajib dalam kurikulum Program Studi Pendidikan Dasar khususnya di STKIP Persada Khatulistiwa. Mata kuliah tersebut diberikan kepada mahasiswa semester IV setiap semester ganjil dengan mata kuliah prasyarat adalah Konsep IPA Dasar. Penting untuk membekali mahasiswa mata kuliah Pembelajaran IPA di SD, sebagai wahana untuk membekali mahasiswa dengan pengetahuan keterampilan, 
dan sikap yang diperlukan untuk melanjutkan pendidikan dan untuk menyesuaikan diri dengan perubahan-perubahan di sekelilingnya.

Menulis buku ajar perguruan tinggi tidak lepas dari mata ajar (mata kuliah), perancangan pengajaran, metode pengajaran, dan bahasa yang digunakan. Jika diskemakan dapat dilihat dalam Gambar 1. Langkah pertama yang harus dilakukan adalah merumuskan tujuan mengajarkan mata kuliah, langkah selanjutnya mempelajari keadaan mahasiswa yang akan menerima mata kuliah yaitu pengetahuan, keterampilan, dan sikap. Langkah selanjutnya adalah memilih dan menyusun topik, menentukan cara pengajaran, membuat tugas untuk kegiatan belajar mengajar, media pengajaran, alat evaluasi pengajaran (latihan dan tugas), dan alat bantu.

Metode Pengajaran yang diberikan hendaknya berorientasi pada mahasiswa dan membatasi diri pada kurikulum. Diskusi hendaknya diarahkan dan diawasi, jangan sampai melantur ke masalah lain. Jangan memberikan tugas secara berlebihan. Banyaknya tugas dan derajat kesulitan disesuaikan dengan kemampuan mahasiswa. Tujuan pemberian tugas agar mahasiswa memantapkan materi yang telah diperolehnya. Bekerja kelompok harus jelas tugas dan hasil yang harus dicapai kelompok. Buku ajar menggunakan bahasa tulisan yang dalam penyampaiannya berlangsung komunikasi searah karena pembaca tidak ada di sekitar penulis. Berkomunikasi dalam menulis buku ajar lebih kompleks bila dibandingkan dengan ceramah.

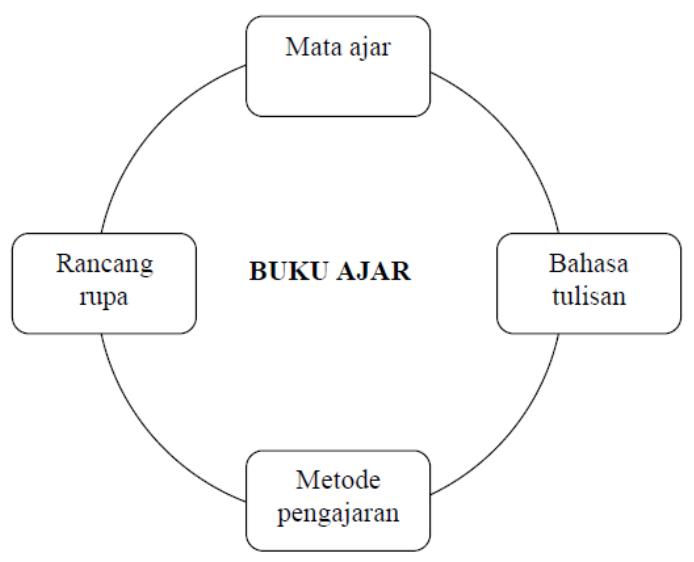

\section{Gambar 1 Menulis Buku Ajar Perguruan Tinggi}


Mata kuliah Pembelajaran IPA SD bertujuan agar mahasiswa: (1) Memperoleh pengetahuan, pemahaman, wawasan tentang kurikulum IPA; (2) Mampu menganalisis fenomena dan permasalahan dalam kurikulum IPA; (3) Mampu membuat silabus IPA dan menguasai komponen-komponen indikator dan tujuan: (4) Menguasai pendekatan dan model pembelajaran IPA di SD; (5) Mampu membuat skenario pembelajaran dan kegiatan-mengajar IPA di SD; (6) Mampu merancang LKS untuk pembelajaran IPA dan mampu membuat alat evaluasi dalam pembelajaran IPA; dan (7) Mampu membuat media pembelajaran, bahan ajar, dan merancang RPP IPA di SD.

Berdasarkan latar belakang tersebut, maka perlu adanya upaya untuk memfasilitasi mahasiswa dalam memahami penerapan pembelajaran IPA SD sehingga tujuan dari penelitian adalah pengembangan buku ajar mata kuliah pembelajaran IPA SD yang layak digunakan bagi mahasiswa Program Studi PGSD.

\section{METODE}

Desain penelitian menggunakan research and development. Desain penelitian mengikuti desain Borg dan Gall dan dimodifikasi sesuai dengan tujuan penelitian yang digambarkan pada gambar berikut.

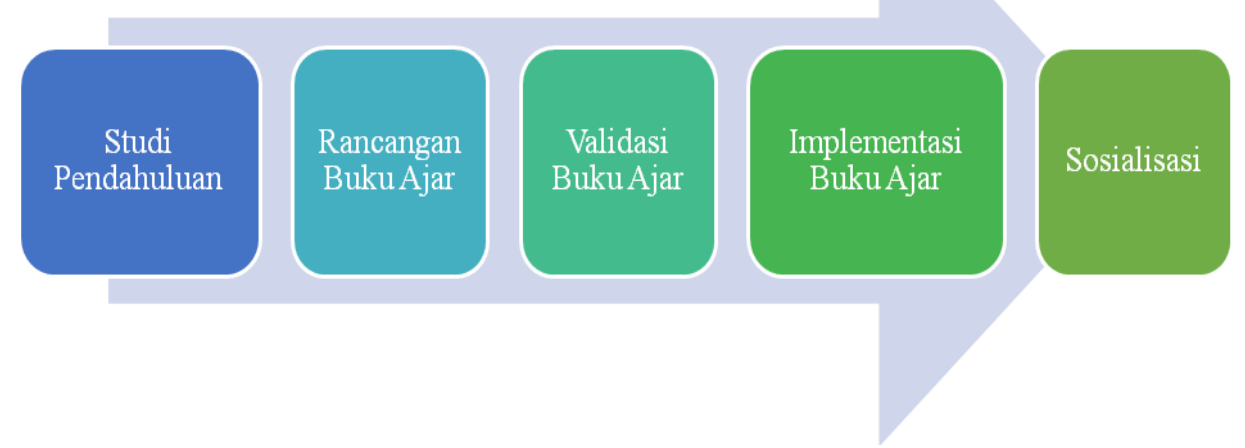

Gambar 2 Tahapan Perancangan Buku Ajar 


\section{Studi Pendahuluan}

Tahap studi pendahuluan merupakan kegiatan research and information collecting, yang kegiatan utamanya adalah studi literarur baik mengkaji sumbersumber yang relevan maupun kajian penelitian terdahulu dan studi lapangan berupa analisis kebutuhan penelitian serta pengamatan lokasi penelitian.

\section{Tahap Perancangan Buku Ajar}

Tahap perancangan buku ajar kegiatannya terdiri dari perencanaan dan penyusunan buku ajar. Buku ajar disusun berdasarkan pada Satuan Ajar Perkuliahan (SAP) dan perkembangan keilmuan yang relevan. Merumuskan penilai kelayakan dan sampel untuk melihat efektivitas. Menentukan prosedur kerja dan uji statistik kelayakan. Hasil dari kegiatan tersebut diperoleh draf desain produk yang siap untuk validasi.

\section{Tahap Validasi}

Tahap validasi bertujuan untuk menyempurnakan produk yang dibuat. Validasi dilakukan oleh pakar yang menguasai bidangnya. Pada tahap validasi dilakukan analisis dan revisi produk yang dibuat. Jika produk yang dibuat kurang baik, maka dilakukan revisi dan selanjutnya divalidasi kembali. Ahli pakar dalam penelitian adalah pakar pembelajaran IPA dan pakar media pembelajaran. Penilaian kelayakan buku juga dilakukan oleh 1 orang dosen pengampu mata kuliah dan 10 Mahasiswa yang sudah menempuh mata kuliah Pembelajaran IPA SD.

\section{Tahap Implementasi}

Tahapan yang mengandung kegiatan utama yaitu uji coba pada pengguna buku yaitu 100 mahasiswa PGSD di STKIP Persada Khatulistiwa Sintang yang menempuh mata kuliah pembelajaran IPA SD. Teknik pengambilan subjek uji coba lapangan dengan purposif dan cluster sampling. Sampel akan dibagi ke dalam 2 (dua) kelompok yaitu eksperimen dan kelompok kontrol. Tujuannya adalah untuk memperoleh data keefektifan penggunaan produk dan keterbacaan buku ajar. 


\section{Tahap Diseminasi}

Diartikan sebagai tahap dissemination and implementation yang mengandung kegiatan sosialisasi dan distribusi. Buku ajar Pembelajaran IPA SD yang telah dinyatakan layak dan efektif untuk diterapkan dapat disosialisasikan kepada publik. Jenis data yang akan dikumpulkan adalah data kualitatif dan kuantitatif. Data kualitatif adalah masukan-masukan pakar dan pengguna buku. Data kuantitatif berupa respon jawaban (skor) mahasiswa terhadap tes yang diujikan. Instrumen yang akan digunakan untuk proses pengumpulan data adalah angket dan tes.

Angket digunakan untuk mengetahui kelayakan produk oleh para pakar, tanggapan dosen pengampu mata kuliah Pembelajaran IPA, dan mahasiswa PGSD. Analisis data implementasi produk dengan deskriptif. Analisis terhadap data hasil uji empiris menggunakan statistik deskriptif persentase. Data hasil implementasi dianalisis dengan uji statistik parametrik, yaitu deskriptif satu sampel. Standar Kualitas Produk Penelitian berdasarkan pada beberapa indikator yaitu: Penilaian pakar, tanggapan dosen dan mahasiswa adalah $\geq 80 \%$. Perolehan hasil belajar kelompok eksperimen adalah $\geq 80 \%$.

\section{HASIL DAN PEMBAHASAN}

\section{Deskripsi Hasil Penilaian Pakar Pembelajaran IPA Sekolah Dasar}

Berdasarkan penilaian produk draf buku yang sudah dirancang diperoleh hasil bahwa buku sudah layak digunakan sebagai buku ajar bagi mahasiswa PGSD. Indikator-indikator penilaian kelayakan pakar pembelajaran IPA disajikan pada Tabel 1 dan indikator penilaian kelayakan untuk pakar media pembelajaran disajikan pada Tabel 2.

Tabel 1 Kisi-Kisi Lembar Penilaian Ahli Materi Pembelajaran IPA SD

\begin{tabular}{lll}
\hline No. & \multicolumn{1}{c}{ Kriteria } & \multicolumn{1}{c}{ Indikator } \\
\hline I. & Aspek Kelayakan Isi & A. Kesesuaian materi dengan KD \\
& & B. Keakuratan materi \\
& & C. Kemutakhiran materi \\
& & D. Mendorong keingintahuan \\
II. & Aspek Kelayakan & A. Teknik penyajian \\
& Penyajian & B. Pendukung penyajian \\
\hline
\end{tabular}




\begin{tabular}{lll}
\hline No. & \multicolumn{1}{c}{ Kriteria } & \multicolumn{1}{c}{ Indikator } \\
\hline & & C. Penyajian pembelajaran \\
III. & D. Koherensi dan keruntutan alur pikir \\
& Kebahasaan & A. Lugas \\
& B. Komunikatif \\
& C. Dialogis dan Interaktif \\
& D. Kesesuaian dengan Perkembangan \\
& E. Kesesuaian dengan KAidah Bahasa \\
\hline
\end{tabular}

Tabel 2 Kisi-Kisi Lembar Penilaian Ahli Media Pembelajaran

\begin{tabular}{cl}
\hline Kriteria & \multicolumn{1}{c}{ Indikator } \\
\hline Aspek Kelayakan & A. Ukuran Bahan Ajar \\
Kegrafikan & B. Desain Sampul BA (Cover) \\
& C. Desain Isi BA \\
\hline
\end{tabular}

Dosen adalah pengguna buku yang menjadi pilihan wajib untuk pengujian kelayakan buku ajar yang dirancang. Setelah pakar pembelajaran IPA dan pakar media pembelajaran menyatakan valid, maka penilai selanjutnya adalah dosen. Indikator penilaian kelayakan oleh dosen disajikan pada Tabel 3.

Tabel 3 Indikator Penilaian Kelayakan Pengguna Buku - Dosen

\begin{tabular}{ll}
\hline No. & Aspek/Indikator dan Butir Pernyataan/Pertanyaan \\
\hline 1 & Kejelasan \\
2 & Kesesuaian dengan Kurikulum \\
3 & Keutuhan Pemahaman/Penerimaan \\
4 & Pengaruh/Dampak \\
5 & Ketepatan Waktu \\
6 & Kepraktisan \\
\hline
\end{tabular}

Buku ajar pembelajaran IPA SD secara khusus dirancang untuk mahasiswa yang sedang menempuh mata kuliah Pembelajaran IPA, sehingga penting untuk mengetahui penilaian dari mahasiswa terhadap produk. Indikator penilaian kelayakan oleh mahasiswa disajikan pada Tabel 4. 
Tabel 4 Indikator Penilaian Kelayakan Pengguna Buku - Mahasiswa

\begin{tabular}{ll}
\hline \multicolumn{1}{c}{ Kriteria } & \multicolumn{1}{c}{ Indikator } \\
\hline Respon & A. Ketertarikan \\
Siswa & B. Materi \\
& C. Bahasa \\
\hline
\end{tabular}

Berdasarkan penilaian produk oleh Pakar pembelajaran IPA SD dan pakar media pembelajaran diperoleh hasil bahwa produk yang dirancang sudah dinyatakan valid dan layak dengan kategori sangat baik. Penilaian pengguna buku dosen pengampu mata kuliah Pembelajaran IPA SD dan 10 (sepuluh) mahasiswa yang menempuh mata kuliah Pembelajaran IPA SD diperoleh kategori hasil sangat baik. Rekapitulasi rata-rata perolehan dirangkum dalam Tabel 5.

Tabel 5 Rangkuman Penilaian Pakar dan Pengguna Buku

\begin{tabular}{|c|c|c|c|}
\hline No & Penilaian & $\begin{array}{l}\text { Persentase } \\
\text { Rata-rata }\end{array}$ & Kriteria \\
\hline 1 & Validasi Ahli Materi IPA & 95,9 & \\
\hline 2 & Validasi Ahli Media & 96,3 & \\
\hline \multicolumn{2}{|r|}{ Rata-Rata } & 96 & Sangat Baik \\
\hline 1 & Kelayakan Buku oleh pengguna Dosen & 90,5 & \\
\hline \multirow[t]{2}{*}{2} & $\begin{array}{l}\text { Kelayakan Buku oleh Pengguna } \\
\text { Mahasiswa }\end{array}$ & 90,1 & \\
\hline & Rata-rata & 90,4 & Sangat Baik \\
\hline
\end{tabular}

Data hasil temuan penelitian dikelompokkan berdasarkan mahasiswa yang dibelajarkan dengan menggunakan buku ajar Pembelajaran IPA SD dengan mahasiswa yang dibelajarkan dengan menggunakan buku teks lainnya. Perbandingan kelompok data hasil belajar berdasarkan temuan penelitian dirangkum dalam Tabel 6.

Tabel 6 Rangkuman Hasil Belajar Implementasi Produk

\begin{tabular}{cccc}
\hline \multicolumn{2}{c}{ Kelas Eksperimen } & \multicolumn{2}{c}{ Kelas Kontrol } \\
\hline $\mathrm{N}$ & 50 & $\mathrm{~N}$ & 50 \\
Jumlah & 4900 & Jumlah & 4250 \\
\hline Rata-rata & 98 & Rata-rata & 85 \\
\hline
\end{tabular}

Setelah dilakukan pengujian prasyarat maka didapatkan hasil bahwa data berdistribusi normal tetapi tidak homogen sehingga digunakan uji hipotesis non 
parametrik. Normalitas data diuji dengan Kolmogorov Smirnov dengan ketentuan jika Asymp. Sig. (2-tailed) $>0,05(\alpha=5 \%)$, maka sebaran data dikatakan berdistribusi normal. Sedangkan untuk menguji homogenitas data penelitian digunakan uji Levene. Kriteria pengujian data dikatakan homogen jika nilai Sig dari Based on Mean yang dihasilkan $<\alpha(0,05)$. Secara ringkas hasil pengujian normalitas dan homogenitas data dirangkum pada Tabel 7.

Tabel 7 Rangkuman Uji Normalitas dan Uji Homogenitas

\begin{tabular}{|c|c|c|c|c|}
\hline $\begin{array}{l}\text { Uji Normalitas } \\
\text { Kelas }\end{array}$ & \multicolumn{2}{|c|}{ Eksperimen } & \multicolumn{2}{|c|}{ Kontrol } \\
\hline $\begin{array}{l}\text { Asymp. Sig. (2-tailed) } \\
\text { Derajat Kebebasan }(\alpha) \\
\text { Keterangan }\end{array}$ & $\begin{array}{l}\text { Pre Test } \\
0,734 \\
0,05 \\
\text { Normal }\end{array}$ & $\begin{array}{l}\text { Post Test } \\
0,620 \\
0,05 \\
\text { Normal }\end{array}$ & $\begin{array}{l}\text { Pre Test } \\
0,615 \\
0,05 \\
\text { Normal }\end{array}$ & $\begin{array}{l}\text { Post Test } \\
0,620 \\
0,05 \\
\text { Normal }\end{array}$ \\
\hline $\begin{array}{l}\text { Uji Homogenitas } \\
\text { Kelas }\end{array}$ & \multicolumn{2}{|c|}{ Eksperimen } & \multicolumn{2}{|c|}{ Kontrol } \\
\hline $\begin{array}{l}\text { Sig. (Based on Mean) } \\
\text { Derajat Kebebasan }(\alpha) \\
\text { Keterangan }\end{array}$ & Tidak & $\begin{array}{l}23 \\
05 \\
\text { omogen }\end{array}$ & $\begin{array}{l}0,037 \\
0,05 \\
\text { Tidak Hc }\end{array}$ & logen \\
\hline
\end{tabular}

Hipotesis penelitian adalah terdapat perbedaan yang signifikan antara kelompok eksperimen dan kelompok kontrol. Pengujian hipotesis menggunakan uji beda dari statistik non parametrik uji Kruskall Wallis karena data yang digunakan berdistribusi normal tetapi tidak homogen. Dari hasil analisis diperoleh hasil p-level 0,000 lebih kecil dari alpha 0,05 $(\mathrm{p}<0,05)$ yang berarti bahwa ada pengaruh penerapan buku ajar mata kuliah Pembelajaran IPA SD terhadap hasil belajar mahasiswa. Dari pengujian hipotesis diperoleh bahwa efektivitas penggunaan buku ajar mata kuliah Pembelajaran IPA SD sebesar 89,31\%. Rangkuman uji hipotesis terlihat pada Tabel 8.

Tabel 8 Rangkuman Uji Hipotesis

\begin{tabular}{cccc}
\hline & p-level & Alpha $(\boldsymbol{\alpha})$ & Kesimpulan \\
\hline 89,31 & 0,000 & 0,05 & Ada Perbedaan signifikan \\
\hline
\end{tabular}




\section{Pembahasan}

Perancangan buku ajar perlu memperhatikan beberapa unsur penting, yaitu buku ajar merupakan buku pelajaran yang ditujukan bagi mahasiswa pada jenjang tertentu. Buku ajar selalu berkaitan dengan mata pelajaran tertentu. Buku ajar merupakan buku standar. Buku ajar ditulis untuk tujuan instruksional tertentu dan ditulis untuk menunjang suatu progam pengajaran tertentu. Sebuah buku ajar dianggap final setelah menunjukkan hasil yang memuaskan dalam mencapai tujuan yang telah ditentukan (Wedyawati dan Lisa, 2017). Dari hasil yang telah disajikan diperlihatkan bahwa rancangan-rancangan produk menunjukkan bahwa dari segi isi produk sudah sesuai dengan kompetensi capaian pembelajaran, isi materi sudah akurat dan materi sudah layak dari segi kemuktahiran serta isi materi mampu mendorong keingintahuan pembaca.

Pada aspek penyajian, produk juga sudah dinyatakan layak artinya dari tehnik penyajian, pendukung penyajian, penyajian pembelajaran serta koherensi dan keruntutan alur pikir sudah memenuhi kriteria. Pada aspek kelayakan bahasa, produk menunjukkan hasil bahwa produk memiliki kriteria lugas, komunikatif, dialogis, interaktif, sesuai dengan kaidah bahasa dan produk sesuai dengan perkembangan peserta didik yaitu mahasiswa. Dalam merancang buku ajar yang layak harus tahapan sebagai berikut: (1) Telaah kurikulum, secara umum yang ditelaah dari kurikulum adalah landasan filosofi yang dijadikan dasar dalam pengembangan kurikulum. Landasan tersebut tercermin melalui pendekatan pembelajaran, tujuan pendidikan, isi, prosedur, dan pengalaman belajar untuk mencapai tujuan, serta sarana penelitian; (2) Penyusunan silabus, tahap berikutnya adalah penyusunan RPS. Tahap tersebut berguna dalam membantu perancangan umum sistematika setiap buku ajar; (3) Pengorganisasian buku, tetap mengikuti struktur tata tulis pada umumnya, yakni diawali dengan pendahuluan, isi, dan penutup. Layaknya sebuah buku, buku merupakan suatu kesatuan yang bermakna; (4) Pemilihan materi, yang dibahas pada setiap bab buku ajar perlu disesuaikan dengan ukuran-ukuran standar berikut: pemilihan materi standar sesuai dengan kurikulum, tujuan pendidikan, keilmuaan, dan relavansinya dengan perkembangan ilmu dan teknologi; (5) Penyajian materi, merupakan panduan terhadap cara 
menyajikan materi yang terdapat di dalam buku ajar. Unsur-unsur yang terdapat di dalamnya adalah: tujuan pembelajaran, pentahapan pembelajaran, menarik minat dan perhatian mahasiswa, kemudahan dipahami, keaktifan mahasiswa, hubungan bahan, norma, soal, dan latihan; (6) Penggunaan bahasa dan keterbacaan, penggunaan bahasa Indonseia yang baik, jelas, dan benar serta bahasa ragam formal/ilmiah dalam penyajian materi adalah keharusan.

Desain cover dan isi buku telah dinyatakan layak oleh validator ahli media, artinya untuk kriteria-kriteria penilaian sudah melampau standar keberhasilan yaitu $\geq 80 \%$. Dalam merancang buku ajar dari penilaian kelayakan ahli media pembelajaran harus sesuai dengan indikator-indikator sebagai berikut: (1) Kesesuaian ukuran BA dengan standar ISO; (2) Kesesuaian ukuran dengan materi isi BA; (3) Penampilan unsur tata letak pada sampul muka, belakang dan punggung secara harmonis memiliki irama dan kesatuan serta konsisten; (4) Warna unsur dan tata letak harmonis dan memperjelas fungsi; (5) Huruf yang digunakan menarik dan mudah dibaca; (6) Tidak menggunakan terlalu banyak kombinasi huruf; (7) Ilustrasi sampul BA; (8) Konsistensi letak; (9) Unsur tata letak harmonis; (10) Unsur tata letak; (11) Tata letak mempercepat halaman; (12) Tipografi isi BA sederhana; (13) Topografi isi modul memudahkan pemahaman; dan (14) Ilustrasi isi. Desain cover luar buku ajar mendapatkan skor berkategori sangat baik. Artinya materi yang terdapat dalam desain buku ajar layak dijadikan referensi ajar pada mata kuliah Pembelajaran IPA SD.

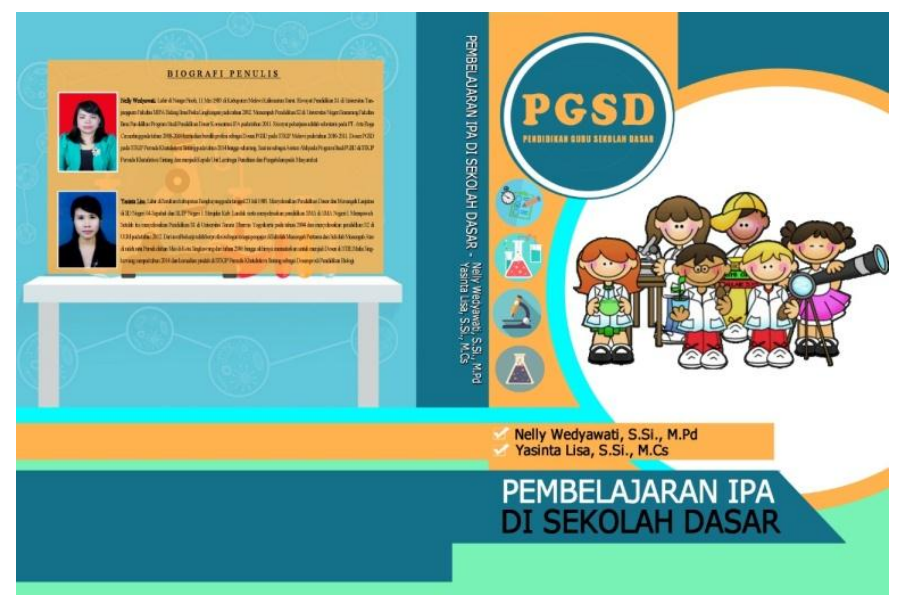

Gambar 3 Cover Buku Ajar 
Hasil dari keefektifan menunjukkan nilai lebih besar dari standar keberhasilan yang ditetapkan yaitu $\geq 80 \%$. Artinya buku ajar telah mampu memenuhi ketertarikan yang meliputi tampilan buku menarik, membuat mahasiswa bersemangat dalam belajar, tidak membosankan, dan mendukung penguasaan konsep pelajaran IPA. Buku ajar mampu memotivasi dan berpengaruh terhadap sikap dan hasil belajar. Dari segi penyajian materi sudah konseptual, mudah dipahami, dan menuntun mahasiswa menemukan konsep sendiri. Mendorong minat berdiskusi dan isi buku memuat evaluasi yang dapat menguji seberapa jauh pemahaman mahasiswa. Aspek kebahasaan juga sudah sesuai dengan kaidah yaitu kalimat dan paragraf yang digunakan dalam buku jelas dan mudah dipahami. Bahasa yang digunakan sederhana dan mudah dimengerti. Huruf yang digunakan sederhana, cukup menarik, dan mudah dibaca

Dengan adanya buku ajar Pembelajaran IPA SD yang telah valid dan layak, maka produk akan bermanfaat untuk proses pembelajaran mata kuliah Pembelajaran IPA atau juga akan bermanfaat bagi pembaca yang memerlukan referensi dalam penelitian bidang pembelajaran sains. Pada proses pembelajaran mahasiswa juga mampu memantapkan ingatan, pemahaman konsep, berpikir kritis, dan pengembangan pengetahuan. Seperti diketahui IPA di sekolah dasar merupakan program untuk menanamkan dan mengembangkan pengetahuan, keterampilan, sikap, dan nilai ilmiah pada siswa (Wedyawati, Lisa, dan Ester, 2018).

\section{SIMPULAN}

Berdasarkan hasil penelitian dan pembahasan, maka dapat disimpulkan: (1) Kelayakan penilaian Buku Ajar Pembelajaran IPA di SD bagi mahasiswa PGSD oleh ahli materi pembelajaran IPA berkategori sangat baik dengan perolehan nilai rata-rata adalah 95,9; (2) Kelayakan penilaian Buku Ajar Pembelajaran IPA di SD bagi mahasiswa PGSD oleh ahli media pembelajaran berkategori sangat baik dengan perolehan nilai rata-rata adalah 96,3; (3) Kelayakan penilaian Buku Ajar Pembelajaran IPA di SD bagi mahasiswa PGSD oleh Pengguna buku yaitu dosen pengampu mata kuliah pembelajaran IPA berkategori sangat baik dengan 
perolehan nilai rata-rata adalah 90,5; (4) Kelayakan penilaian Buku Ajar Pembelajaran IPA di SD bagi mahasiswa PGSD oleh pengguna buku yaitu mahasiswa yang menempuh mata kuliah Pembelajaran IPA berkategori sangat baik dengan perolehan nilai rata-rata adalah 90,1; dan (5) Buku Ajar Pembelajaran IPA di SD bagi mahasiswa PGSD efektif meningkatkan hasil belajar mahasiswa pada mata kuliah pembelajaran IPA di SD dengan rerata nilai adalah 95,31 dan nilai $p$-level $(0.000)<$ alpha $(0.05)$.

Saran yang dapat dituliskan kepada peneliti lain adalah agar dapat merancang buku ajar pada mata kuliah yang sama tetapi dikombinasikan dengan pendekatan-pendekatan lain. Peneliti lain juga dapat merancang berbagai jenis buku lainnya pada mata kuliah yang sama atau dapat mengembangkan buku ajar pada mata kuliah yang berbeda.

\section{DAFTAR PUSTAKA}

Kurniasih, I. 2016. Revisi Kurikulum 2013: Implementasi Konsep dan Penerapan. Jakarta: Kata Pena.

Rizema, P. S. 2013. Desain Belajar Mengajar Kreatif Berbasis Sains. Yogyakarta: Diva Press.

Samatowa, U. 2011. Pembelajaran IPA di Sekolah Dasar. Jakarta: Indeks.

Sugiyono, A. 2017. Metode Penelitian Kuantitatif Kualitatif dan R\&D. Jakarta: Raja Grafindo Persada.

Suroso. 2004. Penulisan Buku Ajar Perguruan Tinggi. Pelatihan Penulisan Buku Sekolah Alkitab Baptis. Semarang: Sekolah Teologia Baptis Indonesia.

Wedyawati, N. \& Lisa, Y. (2017). Developing Integrated Natural Sciences Disaster Mitigation Model For Elementary School Sintang. Education Science and Technology, 164-172.

Wedyawati, N., Lisa, Y., \& Ester, M. 2018. Efektivitas Model Pembelajaran IPA Mitigasi Bencana terhadap Hasil Belajar. Jurnal Pendidikan Dasar Indonesia , 9-13.

Wedyawati, N., Lisa, Y., \& Selimawati, S. 2017. Efektivitas Model Pembelajaran IPA Mitigasi Bencana terhadap Hasil Belajar. Jurnal Edukasi, 261-273. 